\title{
Movement and structural features observed in ice masses, Framnes Mountains, Mac.Robertson Land, East Antarctica
}

\author{
B. A. Marmo \\ School of Earth Sciences, University of Melbourne, Parkville, Victoria 3052, Australia \\ J. DAWSON \\ Department of Geomatics, University of Melbourne, Parkville, Victoria 3052, Australia
}

\begin{abstract}
Ice-movement surveys in the Framnes Mountains from austral summers 1993-94 and 1994-95 are presented with complementary surface elevations and structural interpretations. Surface velocities of $21 \mathrm{~m} \mathrm{a}^{-1}$ have been recorded in Ice Stream B and $31 \mathrm{~m} \mathrm{a}^{-1}$ in Ice Stream C. The flow rate varied between 11.6 and $21.0 \mathrm{~m} \mathrm{a}^{-1}$ over a lateral range of $2.1 \mathrm{~km}$ west of Rumdoodle Peak and between 17.1 and $31.5 \mathrm{ma}^{-1}$ over $2 \mathrm{~km}$ west of Mount Parsons. Two ice streams of relative high flow between the central Masson and David Ranges and several zones of incremental increase in flow rate have been identified within Ice Stream B, using shear-sense criteria based as ice-fracture geometry and subsequent deformation of crevasse traces. These zones of localized strain correlate with ice-flow survey measurements.
\end{abstract}

\section{INTRODUCTION}

The glacial system that flows through the Framnes Mountains, Mac.Robertson Land, East Antarctica (Fig. 1) consists of three outlet glacial streams, divided by the Masson and David Ranges, moving at between 15 and $40 \mathrm{~m} \mathrm{a}^{1}$. These ice streams cover approximately $2400 \mathrm{~km}^{2}$ and help drain the East Antarctic ice sheet into Holme Bay. A previous study has been made of the glacial system focused on the Casey Range area, Forbes Glacier and the Mawson area by Kizaki (1969a, b). In the summers of 1993 94 and 1994-95, ground-based surveys were conducted using differential GPS methods to determine the localization of 155 strain markers divided into five strain grids. Both static and kinematic GPS procedures were employed. Work has concentrated on the ablated blue-ice areas, which comprise one-third of the glacial system. Ablation rates are between 150 and $350 \mathrm{~mm} \mathrm{a}^{-1}$. These regions have been selected in order to study the relationship between variations in ice-flow and ice-fracture geometries. Several different fracture patterns have been recognized and are used to indicate localized shear sense. The development of these different patterns is controlled by surface topography and by changes in the ice-flow rate.

\section{SURVEY METHODS}

Five strain grids have been established using $6 \mathrm{~m}$ lengths of bamboo cane as strain markers. The survey has concentrated on high shear-strain regions identified by ice morphology from aerial photographs. Two of these grids consist of a series of lines across Ice Stream A and Ice Stream B with canes spaced between $700 \mathrm{~m}$ and $1 \mathrm{~km}$ apart (Fig. 1). West of Rumdoodle Peak and Fearn Hill are fine box grids with canes spaced between 200 and $300 \mathrm{~m}$, and west of Mount Parsons are two traverse lines with canes spaced $200 \mathrm{~m}$ and the lines are separated by $1.5 \mathrm{~km}$ with a longitudinal line of five canes joining them (Fig. 1). Seven survey control stations have been established in bedrock using steel pipe $20 \mathrm{~mm}$ in diameter in order to conduct GPS measurements on all strain markers. There are three control stations in the David Range, three in the north Masson Range and one at Mount Henderson (Fig. 1).

To provide a permanent reference, seven survey control stations have been established on rock; this is in addition to a permanent Australian Surveying and Land Information Group (AUSLIG) monument, AUS64, located at Mawson Station. Each station consists of a $20 \mathrm{~mm}$ diameter steel rod drilled to a depth of $200 \mathrm{~mm}$. Three stations are located in the David Range, three in the north Masson Range and another in the Mount Henderson area. All the survey-control stations were measured with GPS survey equipment and each of the markers was measured using GPS and/or conventional survey techniques. The majority of the surveys were undertaken with two single-frequency Ashtech M-XII receivers and a single-frequency Ashtech MS-XII receiver; also, two dual frequency Wild GPS System 200 Leica receivers were utilized during the 1994-95 season. GPS data from a dual frequency Rogue SNR-8100 receiver permanently located at Mawson Station has also been incorporated into the data reductions. Conventional survey measurements were made with a Sokkisha Set 


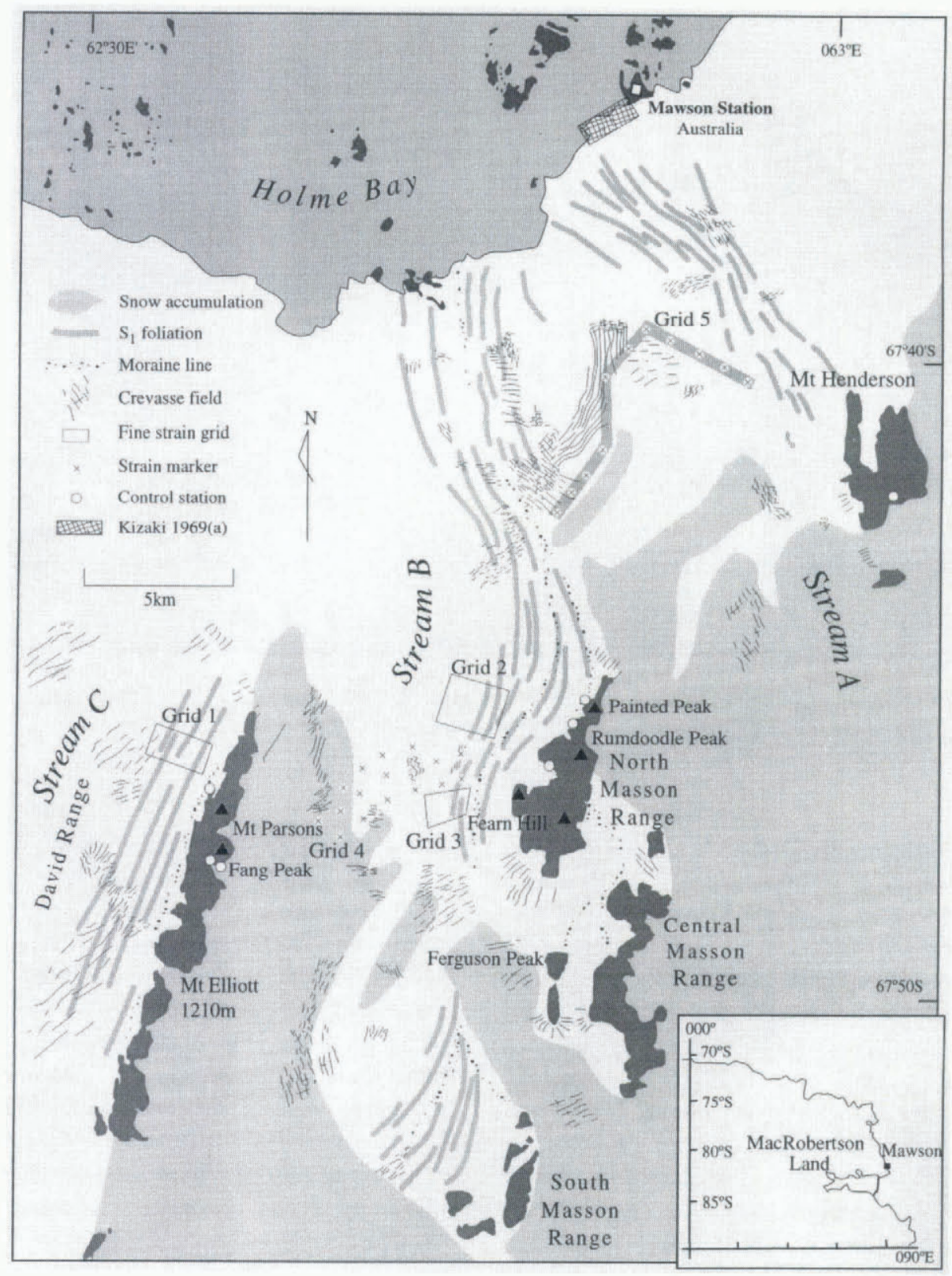

Fig. 1. Glacial system of the Framnes Mountains, Mac.Robertson Land, with major flowlines and crevasse fields. Localities of strain grids and survey control for GPS surveys are indicated. Ice elevations and velocity vectors established from these grids are shown in Figure 3. Inset is East Antartic ice sheet with the Mawson Station area shown.

4C Total Station, with distance, horizontal angles and vertical angles measurements used to determine marker locations.

Using the Ashtech receivers, strain markers were surveyed with observation sessions generally ranging from 30 to $100 \mathrm{~min}$ over distances of $1-20 \mathrm{~km}$. Observation periods were determined, accounting for length of base line and satellite geometry. GPS base lines between survey-control stations were measured using observation periods of $60-180 \mathrm{~min}$ over distances $3-20 \mathrm{~km}$. Using the Leica receivers, the survey-control stations and strain markers were measured with observation times ranging from 2 to $30 \mathrm{~min}$.

Where possible, GPS observations were made to the original surface-marker position. Tilting due to melt-out, making set-up directly over the marker impossible. In most cases, the receivers were set up approximately $30 \mathrm{~mm}$ from the marker and a magnetic bearing and offset distance used to relate the marker position to each GPS observation.

The approximate coordinates of the Mawson Rogue GPS receiver and monument (AUS64) have been used as absolute reference for all survey measurements which have been made on the WGS84 ellipsoid. The coordinates of AUS64 are s supplied by AUSLIG.

\section{RESULTS}

In 1993 94, strain grids 1, 2 and 4 were established (Fig. 1), and strain grid 3 was put in place and surveyed early in the 1994-95 season. All grids were surveyed again late in 199495 and movement vectors have been obtained by comparing relative positions. The scalar component of these vectors has been standardized to movement over $365 \mathrm{~d}$ (Fig. 2). This may result in an overestimate of 


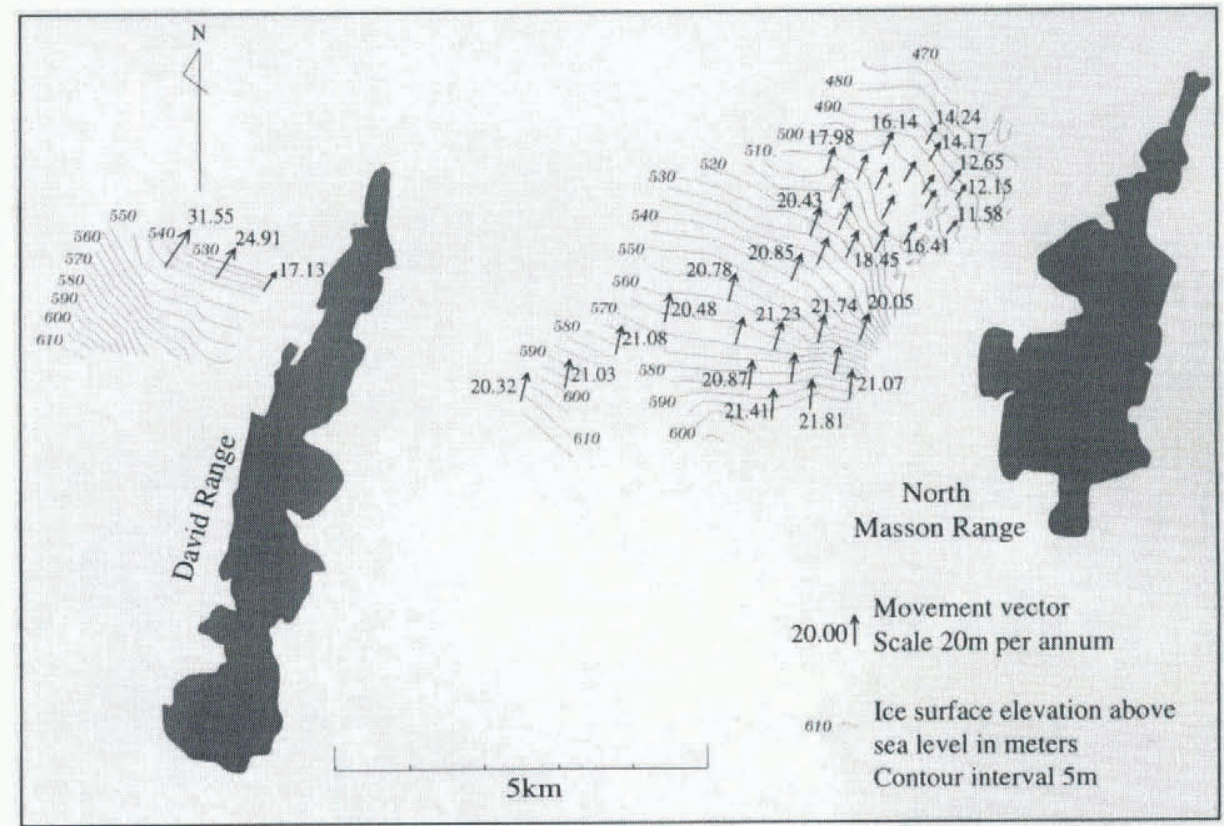

Fig. 2. Summary of velocity vectors for strain grids obtained from GPS survey data from the summer seasons of $1993-94$ and 1994 95. Vector lengths have been scaled to represent velocity.

annual displacement for strain grid 3, as movement has been calculated from one summer's survey when the velocity may be higher than average. Relative movement within strain grid 3 is still valid.

All conventional and GPS measurements have been processed using a least-squares-adjustment technique, with standard deviations marked in each coordinate being to the sub-centimetre level. The offset measurement from the GPS instrument to the strain marker also has an error of $1 \mathrm{~mm}$ and the magnetic bearing results in a position error of $\pm 0.3- \pm 0.5 \mathrm{~mm}$. Larger errors result from movement of the bamboo canes due to melting around the base during summer. With these movements considered, the overall calculation error in the positions is believed to be within $50 \mathrm{~mm}$. The maximum standard deviation for all displacement vectors is $100 \mathrm{~mm}$ and $0^{\circ} 15^{\prime}$.

Ice-velocity calculations have been summarized in Figure 2. West of David Range, laminar flow has been recorded with an increasing flow rate to the west from 17.13 to $31.55 \mathrm{~m} \mathrm{a}^{-1}$ over $2 \mathrm{~km}$. The ice west of Rumdoodle Peak has a divergent flow with $20^{\circ}$ difference in the orientation of vectors. The flow rate recorded by grid 2 increases to the west from 11.57 to $20.94 \mathrm{~m} \mathrm{a}^{-1}$ over $1.8 \mathrm{~km}$ but decreases downstream by $3-4 \mathrm{~m} \mathrm{a}^{-1}$. West of Fearn Hill, the maximum velocity of $22.29 \mathrm{~m} \mathrm{a}^{-1}$ runs through the centre of grid 3. The margins of grid 3 flow approximately $0.5-1 \mathrm{~m} \mathrm{a}^{-1}$ slower than the centre. There is not a pronounced flow gradient through the centre of Ice Stream B but a low of $21.03 \mathrm{~m} \mathrm{a}^{-1}$ is recorded at the centre of grid 4 flanked by ice moving at approximately $0.5 \mathrm{~m} \mathrm{a}^{-1}$.

\section{ICE FOLIATION}

Two foliations have been identified within the glacial system. A well-developed foliation $\left(S_{1}\right)$ occurs as alter- nating light and dark layers of blue ice that are metres wide and hundreds of metres long (Fig. 3). The $\mathrm{S}_{1}$ foliation parallels flow and is best developed west of Masson and David Ranges and west and north of Mount Henderson (Fig. 1). Bubbles in the light bands are $\sim 1 \mathrm{~mm}$ in diameter and evenly distributed with $\sim 5 \mathrm{~mm}$ separating each bubble. The darker bands have noticeably fewer bubbles which are randomly dispersed through the ice (separated by $1-20 \mathrm{~mm}$ ) and the bubble size also varies greatly from $1 \mathrm{~mm}$ to $10 \mathrm{~mm}$. The $S_{1}$ foliation is produced by inhomogeneities within the accumulation zone becoming flattened and rotated by progressive simple shear as described by Hooke and Hudleston (1978).

A later foliation $\left(\mathrm{S}_{2}\right)$ locally overprints the $\mathrm{S}_{1}$ foliation either at a high angle or orthogonally. The foliation is defined by fine bubbly layers less than $1 \mathrm{~mm}$ wide and individual layers extend several metres and dissect each other at low angles $\left(<5^{\circ}\right)$. The bubbles are fine $(<1 \mathrm{~mm})$ and very closely packed. In regions where $S_{2}$ is well developed the layers are separated by $50-100 \mathrm{~mm}$. The $\mathrm{S}_{2}$ foliation appears to have been produced by annealing of fracture traces or the closure of small fracture. Its orientation is controlled by the passive rotation of these traces during shearing and transportation of the ice mass.

\section{CREVASSES AND CREVASSE-TRACE GEOMETRY}

Widespread tensional fracturing occurs throughout the glacial system. Most common are en échelon-style crevasses that occur in simple shear environments, zigzag crevasses that form in areas of divergent flow and linear crevasses produced by longitudinal extension. Crevasse traces are extensive and occur as coarse-grained, clear ice that has formed by open fractures becoming filled with snow and/or water which has become frozen (Hambrey and Milnes, 1977). Where crevasse traces are not passively transported large distances, they can be 

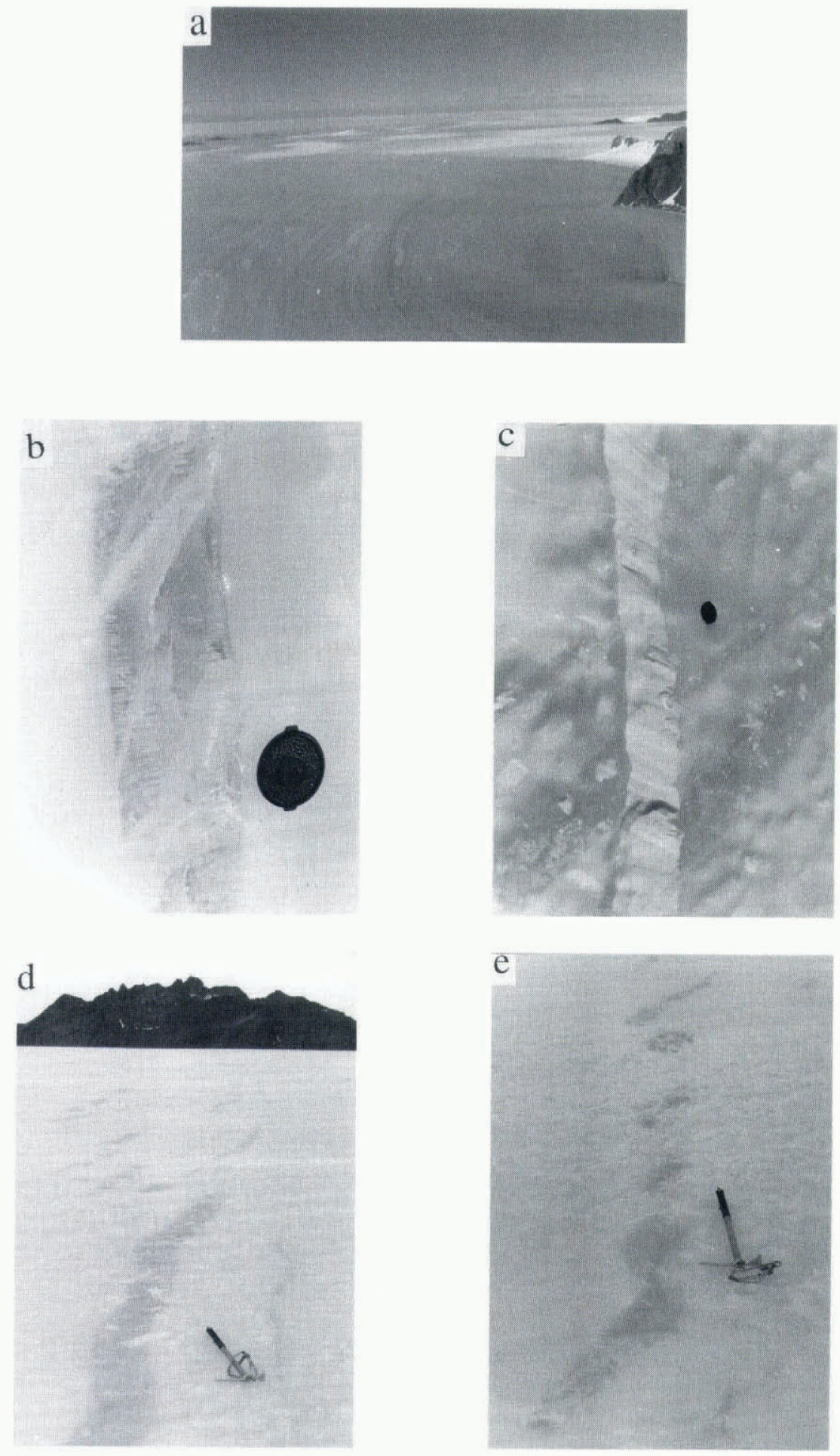

Fig. 3. Photographs of flowlines and structural features in the Framnes Mountains. (a) $S_{1}$ developed west of Masson Range. On the right is Fearn Hill in the middle distance with Painted Peak behind it and the northern section of the Mount Henderson Massif in the background. Aerial oblique photograph taken from $300 \mathrm{~m}$ above the ice surface. The base width of the photograph is approximately $5 \mathrm{~km}$. (b) Fracture trace with a suture plane defined by fine bubbles. Elongated bubbles perpendicular to the trace are produced by crystal growth inward from the fracture wall. (c) Dextral offset of fracture traces by an active crevasse. The fracture traces have been passively transported into the crevasse field from a different field $1.3 \mathrm{~km}$ upstream. ( $d$ and e) Linear-crevasse traces in $(d)$ are transported $500 \mathrm{~m}$ downstream and become boudinaged by sinistral shears, resulting in pinch-swell structures (e). The ice-axe scale is $1 \mathrm{~m} \mathrm{long}$.

considered to reflect local stress regimes. Commonly, the trace has a median suture composed of a well-defined plane of fine bubbles midway between the walls (Fig. 3).
It has been noted that crevasse traces persist for some distance downstream from crevasse fields but eventually become re-incorporated into the blue ice due to an 

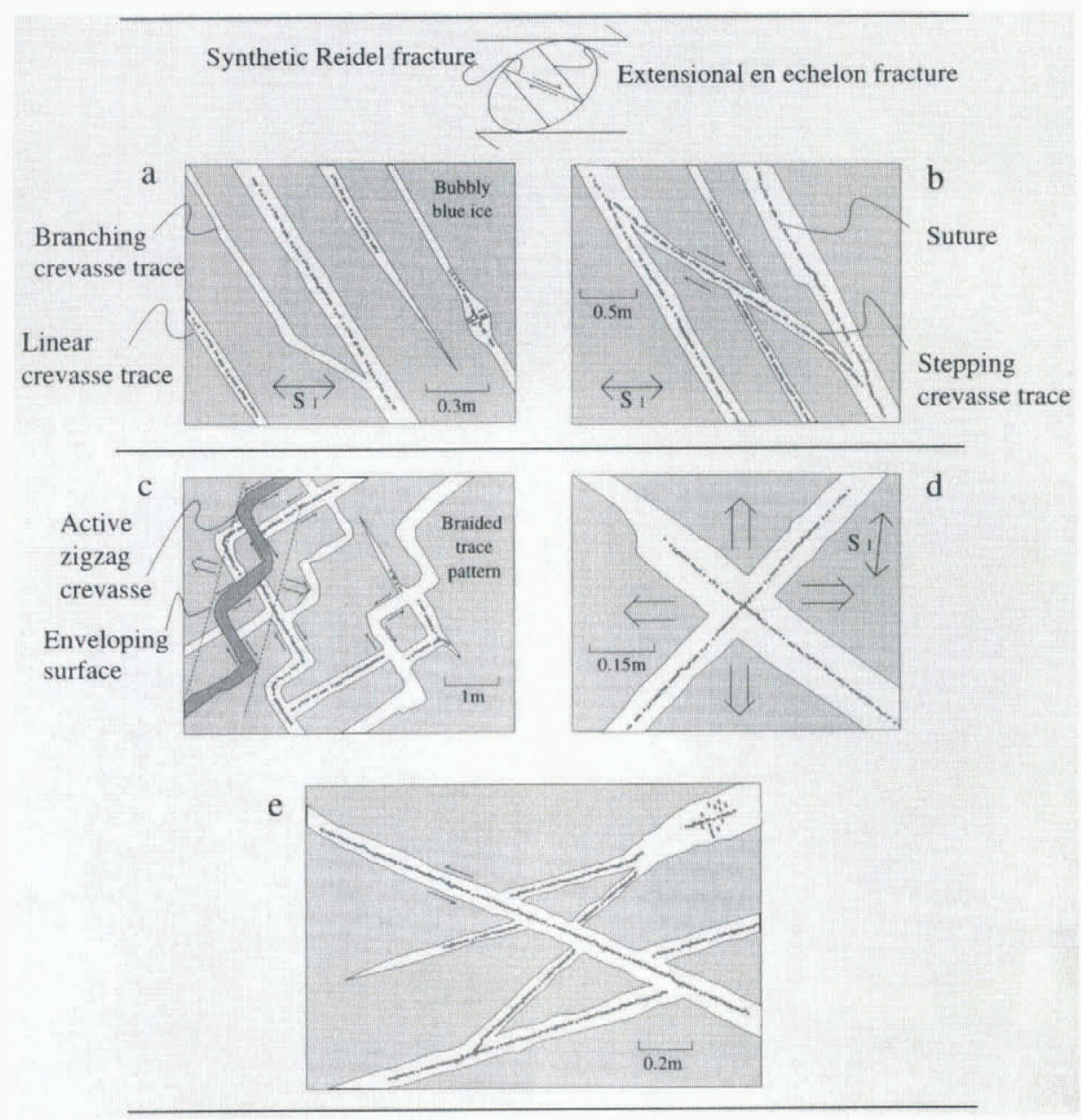

Fig. 4. Line sketches of important structural features within the Framnes Mountains. ( $a$ and $b$ ) En échelon fracture array formed in a dextral regime with linear extensional fractures (a) are initiated $45^{\circ}$ clockwise from $S_{l}$ and (b) a stepping fracture initiated as a synthetic reidel fracture at approximately $10^{\circ}$ clockwise from $S_{1}$. An older linear en échelon crevasse trace has been offset by the stepping trace, indicating dextral shear. The connection of the medial sutures suggests that the linear fractures and the stepping fracture were contemporaneous. (c) Zigzag crevasses develop due to dilation perpendicular to their enveloping surface. Alternate segments have opposite senses of shear. Overprinting and refreezing of successive fractures result in a braided fracture pattern. (d) Conjugate set of fractures that were active contemporaneously. Neither of the medial sutures are offset as crystal growth from all four walls are at the same time. (e) Sinistral offset of linear-fracture traces and a stepping fracture. These fractures have been passively transported into a new crevasse field and deformed.

annealing process. Traces that are $100 \mathrm{~mm}$ wide persist for only $1-1.5 \mathrm{~km}$ from the region where they were initiated.

The crevasses and crevasse traces generally form a regular geometric pattern. The occurrence and style of such patterns is controlled by surface topography and the variations in flow rate and direction. The two commonest styles of fracturing are linear or lenticular fractures and zigzag fractures. Linear crevasses are greater than $10 \mathrm{~m}$ in length and have planar walls. Lenticular crevasses are less than $10 \mathrm{~m}$ long, $0.1-0.5 \mathrm{~m}$ wide at the centre and terminate at a point. Both occur when lines of parallel flow move over an ice wave, resulting in dilation perpendicular to flow and the development of parallel fractures. When the ice wave is broad, linear crevasses develop, whereas when the geometry of the wave changes over a short distance then lenticular crevasses form. Linear crevasses commonly form down-flow from lenticular crevasses, indicating that the tips of lenticular crevasses may continue to propagate to form linear features if the stress regime is appropriate. Zig-zag crevasses occur when divergent flow occurs over an ice wave. They are produced by dilation normal to the enveloping surface, resulting in the development of alternating dextral and sinistral segments (Fig. 4). Overprinting of successive zigzag crevasses produces a braided fracture-trace pattern (Fig. 4).

A less common crevasse pattern is segmented or en échelon crevassees which occur on the curved margins of ice waves. These consist of parallel lenticular-shaped segments that parallel the linear crevasses at the head of the ice wave. The segments are connected at depth by a parent fracture that extends radially from the centre of the ice wave and is oblique to the orientation of the segments (Fig. 5). A rotation of the stress field near the surface of the ice wave results in the break-down of the single-parent fracture into segments as the array of smaller segments has relatively less surface area to sweep out, in order to remain perpendicular to $\sigma_{3}$ (minimum principle-stress direction) (Pollard and others, 1982).

Lateral or longitudinal changes in flow rate, or variations in flow direction, result in fracturing indepen- 


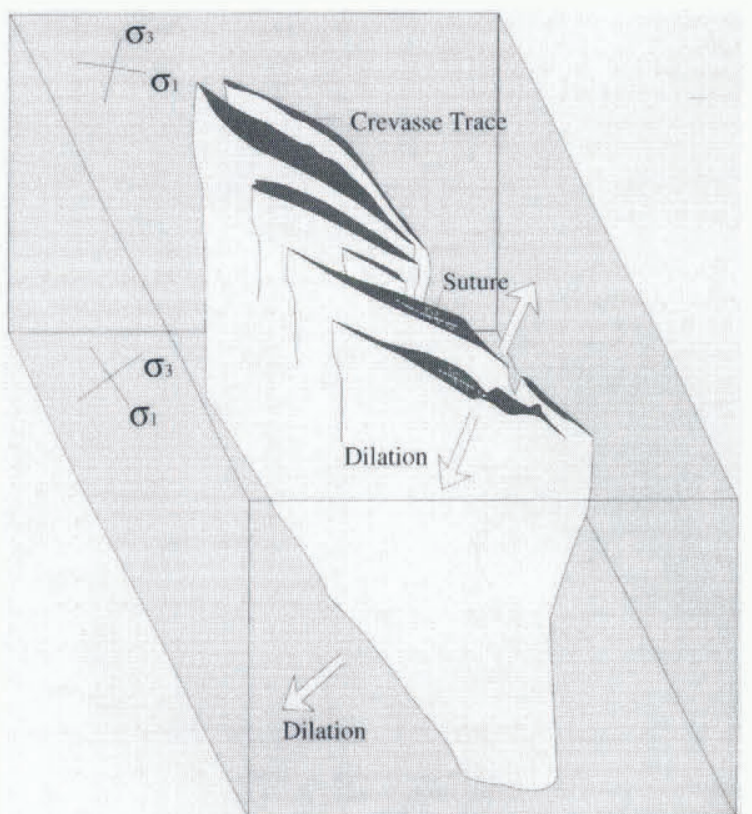

Fig. 5. Development of segmented crevasse geometry; surface geometry from field observations of the crevasse field west of Mount Elliott and apparent three-dimensional geometry. As the parent fracture propagates upward, the stress regime appears to rotate anti-clockwise.

dent of surface topography. In areas of divergent flow, there is zigzag fracturing that is identical to that occurring on ice waves. Extensional shear fractures form large en échelon arrays along the upstream margin of the glacier at $45^{\circ}$ to the flow direction. They are also produced in response to localized lateral changes in flow rate within the confines of the glacial system. Fractures are laterally extensive $(20-50 \mathrm{~m})$ and form parallel arrays at the surface. Lenticular fractures also occur within individual light layers of the $\mathrm{S}_{1}$ foliation. Some linear fractures have sub-parallel branching features that are initialized at a low angle to the linear fracture and then curve into parallelism with the dominant fracture set. It is also common to see fracture that steps between two linear fractures at a low angle $\left(5-20^{\circ}\right)$. Sutures in fracture traces indicate that both branching and stepping fractures were active contemporaneously with the linear fractures to which they are attached (Fig. 4).

\section{SHEAR-SENSE CRITERIA}

Determination of shear sense is a critical constraint in the study of a glacier's flow characteristics. The most prominent shear-sense indicator is the offset of crevasse traces by either active or younger crevasse traces (Fig. 3). These occur when crevasse traces are passively transported into an active crevasse field or when traces of more than one orientation are initiated in the same field, such as stepping-fracture pattern and braided-fracture pattern.

The orientation of en échelon arrays, stepping fractures and rotated crevasse traces relative to $S_{1}$ (flow direction) can also be used as shear-sense criteria. In a dextral regime, extensional en échelon fractures make $45^{\circ}$ clockwise angles with $\mathrm{S}_{1}$, and in a sinistral regime, $45^{\circ}$ anti-clockwise. The orientation of stepping-crevasse traces
Light layer of S1 Dark layer of S1

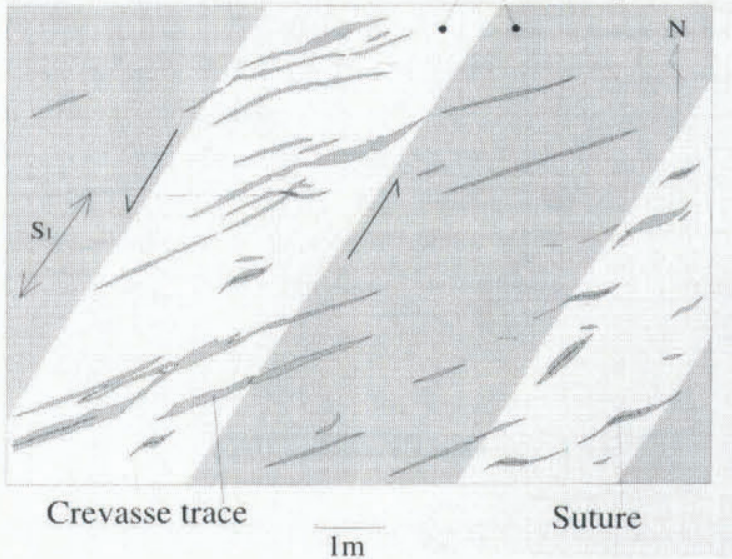

Fig. 6. Lenticular fractures developed predominantly within light bands of $S_{I}$. These fractures have been rotated by a dextral shear. These are overprinted by a linear en échelon array that bisects both the dark and light layers of $S_{\text {I. }}$.

also reflects the orientation of shear strain as they appear to be initiated as synthetic $\mathrm{R}_{1}$ Reidel shear fractures. This is reflected in the offsets of the older traces with shear across the stepping fracture sympathetic with an en échelon array. Initially, the stepping trace makes an acute angle clockwise from the flow direction in a dextral regime, and anti-clockwise in a sinistral regime. It should be noted that the orientation of the traces with respect to each other and $\mathrm{S}_{1}$ changes with ongoing deformation. However, no cases of traces being rotated more than $10^{\circ}$ have been noted.

Rotation of crevasse traces is a potential shear-sense and shear-strain indicator, except that the component of rotation due to pure shear strain cannot be estimated. In areas where there is localized differential shear strain, such as within layers of $\mathrm{S}_{1}$, a sigmoidal pattern develops which can be used as a shear-sense indicator. In places, the lenticular en échelon fractures within the light lavers in $\mathrm{S}_{1}$ that were initially at $45^{\circ}$ to the flow direction, are progressively rotated by simple shear (Fig. 6). A regular signoidal pattern results, indicating that shear strain was greater at the centre of the layer than at the margins and that pure shear was not important in forming the geometry. It also indicates that the shear strain is partitioned into the light layers, as they are relatively less competent than the dark layers.

In some regions, the thick crevasse traces $(>100 \mathrm{~mm})$ become boudinaged and pinch-swell structures develop. A gradual downstream progression, from linear traces formed at or near a crevasse field to the development of metre-length boudins, can be observed west of the central Masson Range (Fig. 4). The lack of bubbles and relatively coarse-grained nature of the ice that infills the crevasse traces makes them more competent in comparison to the surrounding bubbly blue ice. The presence of boudins suggests that there is an extensional regime sub-parallel to the orientation of the crevasse traces. The boudins observed west of the central Masson Range appears to have been produced by extension normal to flow in order to fill the void north of Ferguson Peak. The relative position of the boudins is useful for shear-sense determin- 
ation. The boudins west of the central Masson Range appear to have been produced by sinistral shears breaking up the crevasse traces. Care must be taken, as similar geometries could produce back-rotation of the crevasse traces within a dextral regime (Hanmer and Passchier, 1991). The orientation of the intact traces upstream is known to parallel the orientation of the boudins, so backrotation can be excluded as a possiblity and shear sense can be obtained.

\section{STRUCTURAL INTERPRETATION}

Macroscale zones of localized strain have been identified, using the orientation and sense-of-movement of fractures. These zones are hundreds of metres wide and kilometres long (Fig. 7). The most prominent are the dextral zones that begin between the north Masson and David Ranges that extend for tens of kilometres and separate areas of fracture-free ice. These zones of localized shear strain represent regions where the flow rate is increasing laterally (to the west), whereas the zones of fracture-free ice are regions where the flow rate is constant.

Between the central Masson and David Ranges, a zone of sinistral shear between two zones of dextral shear indicates there are at least two streams of high flow rate, one close to David Range and a second $3 \mathrm{~km}$ west of

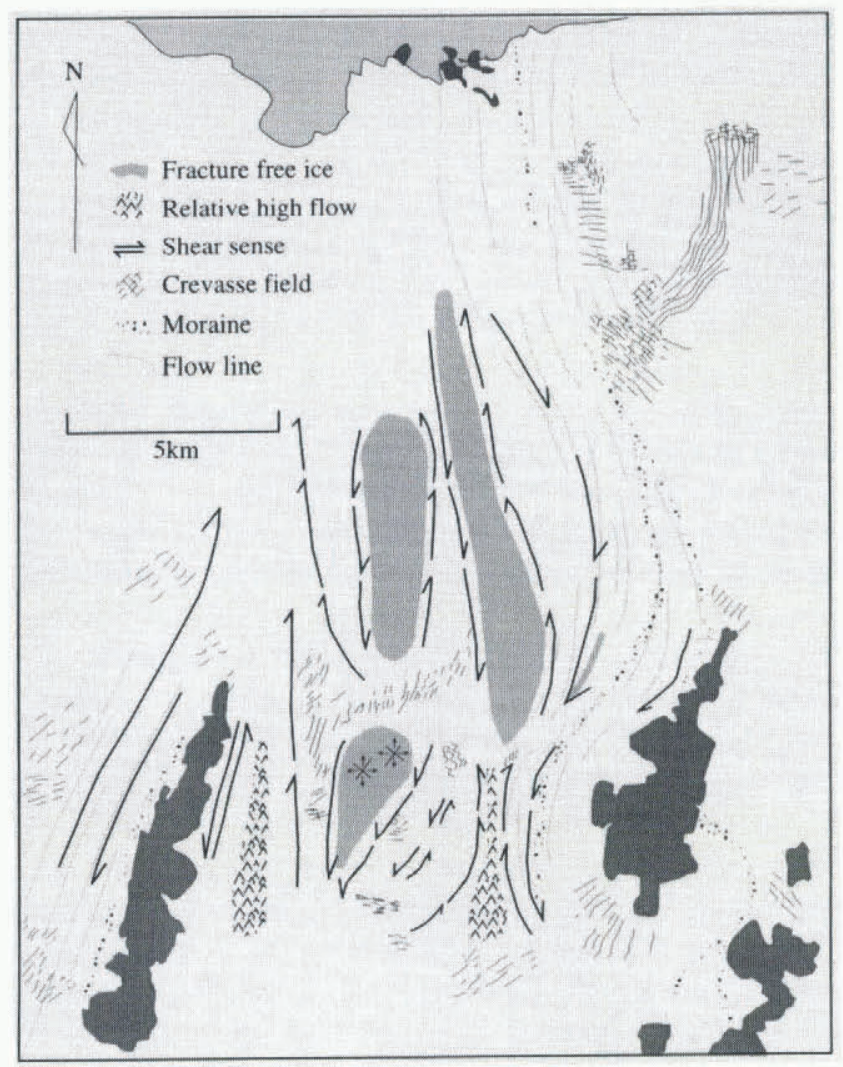

Fig. 7. Schematic diagram of zones of localized strain developed using shear-sense criteria and fracture geometries. A westward incremental increase of strain is indicated by zones of localized dextral shear in the northern section of Ice Stream B. Between David Range and Masson Range are two zones of high flow indicated by alternating zones of shear sense.

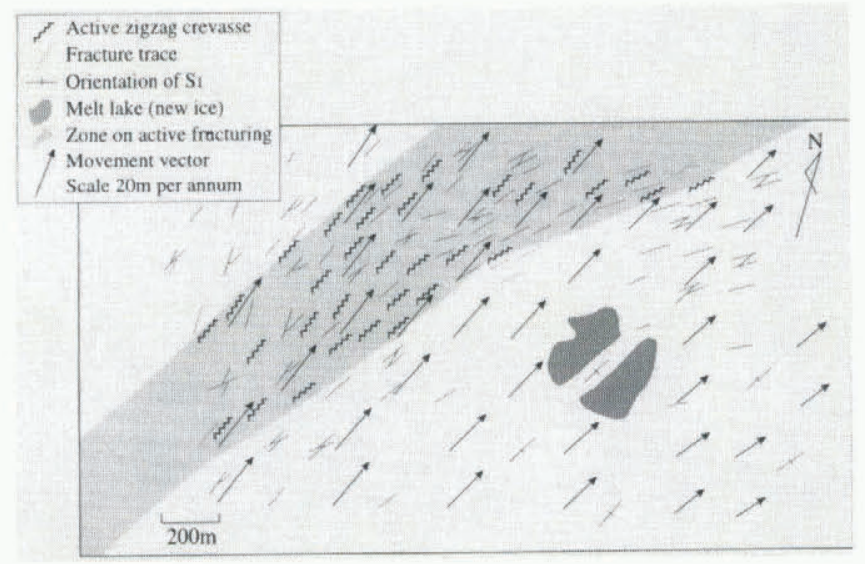

Fig. 8. Fracture-pattern array in the grid 2 area with velocity vectors. The vectors indicate a $20^{\circ}$ divergence of flow from west to east. A zone of active zigzag fractures has developed through the centre of the grid. The enveloping surfaces of these crevasses parallel the flow direction, suggesting that they are produced by dilation perpendicular to flow. The ice in the southeastern corner is fracture-free. In the north and northeast are linear and stepping fractures that indicate dextral shear. This is reflected in the westward increase of flow rate.

Fearn Hill (Fig. 7). Downstream from the sinistral zone is a zone of dominantly dextral shear. The transition between the two zones is characterized by zigzag crevasses which denote lateral extension. The area immediately west of the sinistral shear zone is relatively fracture free but does have some conjugate fractures that indicate a component of pure shear (Fig. 4d), which are consistent with a zone of low flow rate bordered by a sinistral shear zone to the east and a dextral shear zone to the west.

Zones of localized strain are also produced by the interaction of the different streams. A dextral en échelon fracture array has developed in Ice Stream B along its margin with Ice Stream C, north of David Range. This suggests that Ice Stream C has a higher flow rate, resulting in dextral shearing within Ice Stream B. On the east margin of Ice Stream B, stepping fractures and offsets of older crevasse traces indicate sinistral shear normal to flow. These appear to be produced by westward pressure from Ice Stream A as it flows around north Masson Range and into Ice Stream B.

Through the centre of strain grid 2 is a localized region of zigzag crevasses that are up to $15 \mathrm{~m}$ long and $50 \mathrm{~mm}$ wide. These fractures are produced by the divergence of flow west of Rumdoodle Peak and Painted Peak, which is reflected in the orientation of flowlines $\left(S_{1}\right)$ and velocity vectors (Fig. 8). The enveloping surfaces of zigzag crevasses parallel the orientation of velocity vectors, suggesting that dilation is perpendicular to the flow direction. The presence of these crevasses also enables longitudinal compression, explaining why the ice velocity is reduced downstream.

\section{DISGUSSION AND CONGLUSIONS}

The macroscale structures also appear to be correlated 
with initial surface flow-rate measurements in the outlet glaciers in the Framnes Mountains. The zone of relative high flow west of north Masson Range was identified using structural data that is reflected by the centre of strain grid 3 flowing $0.5 \mathrm{ma}^{-1}$ faster than its eastern and western margins. The survey data are also in good agreement with the zone of fracture-free ice between David and north Masson Ranges where there is only a $0.05 \mathrm{ma}^{-1}$ lateral change in flow rate over $1 \mathrm{~km}$. This region is bounded by a sinistral zone to the east and a dextral zone to the west, resulting in it flowing $0.5 \mathrm{ma}^{-1}$ slower relative to the neighbouring regions.

The macroscale zones of localized shear strain suggest that the lateral change in flow rate is incremental. The incremental changes in flow rate are controlled by the development of these zones of localized strain-ductile deformation in the downslope movement of the ice masses. Shear-sense criteria used to interpret large-scale structures within the glacial system appear to be confirmed by the survey results. In the northeastern corner of strain grid 2 is a well-developed set of linear extension and stepping fractures, which indicated a dextral-shear regime. This is reflected by the westward increase in flow rate calculated from initial survey results. The orientation of both the linear fractures and the stepping fractures relative to the velocity vectors are as predicted.

\section{ACKNOWLEDGEMENTS}

We should like to extend thanks to all officers and expeditioners of the Australian National Antarctic Research Expeditions (ANARE) for assistance and cooperation during the 1993-94 and 199495 field seasons. C. Wilson of the School of Earth Science, University of Melbourne, helped in the preparation of the programme and provided valuable suggestions to earlier versions of this paper. P. Collier of the Department of Geomatics, University of Melbourne, also provided many valuable suggestions regarding the conduct of the programme. Logistical support by the Australian Antarctic Division, and by the Department of Geomatics, University of Melbourne, and financial support from ASAC grant number 599 are gratefully acknowledged. Thanks are also due to the Australian Land Information Group for supplying GPS survey data.

\section{REFERENCES}

Hambrey, M.J. and A. G. Milnes, 1977. Structural geology of an Alpine glacier (Griesgletscher, Valais, Switzerland). Eclogae Geol. Helv., 70 (3), 667-684.

Hamner, S. and C. Passchier. 1991. Shear sense indicator: a review. Ottawa, Canada Communications Group.

Hooke, R. LeB. and P.J. Hudleston. 1978. Origin of foliation in glaciers. 7. Glaciol., 2083$), 285-299$.

Kizaki, K. 1969a. Fabric analysis of surface ice near Casey Range, East Antarctica. f. Glaciol., 8 (54), 375-383.

Kizaki, K. 1969b. Ice-fabric study of the Mawson region, East Antarctica. \%. Glaciol., 8(53), 253-276.

Pollard, D. D., P. Segall and P. T. Delaney. 1982. Formation and interpretation of dilatant échelon cracks. Geol. Soc. Am. Bull., 93, 1291-1303. 